\title{
TU/e EnмHONEN

\section{A general inversion cell, obtained from two random contra- parallelogram linkages, interconnected at the vertices of a parallelogram}

\section{Citation for published version (APA):}

Dijksman, E. A. (1994). A general inversion cell, obtained from two random contra-parallelogram linkages, interconnected at the vertices of a parallelogram. Mechanism \& Machine Theory, 29(6), 793-801.

https://doi.org/10.1016/0094-114X(94)90078-7

DOI:

10.1016/0094-114X(94)90078-7

Document status and date:

Published: 01/01/1994

\section{Document Version:}

Publisher's PDF, also known as Version of Record (includes final page, issue and volume numbers)

\section{Please check the document version of this publication:}

- A submitted manuscript is the version of the article upon submission and before peer-review. There can be important differences between the submitted version and the official published version of record. People interested in the research are advised to contact the author for the final version of the publication, or visit the $\mathrm{DOI}$ to the publisher's website.

- The final author version and the galley proof are versions of the publication after peer review.

- The final published version features the final layout of the paper including the volume, issue and page numbers.

Link to publication

\footnotetext{
General rights

- You may freely distribute the URL identifying the publication in the public portal. follow below link for the End User Agreement:

www.tue.nl/taverne

\section{Take down policy}

If you believe that this document breaches copyright please contact us at:

openaccess@tue.nl

providing details and we will investigate your claim.
}

Copyright and moral rights for the publications made accessible in the public portal are retained by the authors and/or other copyright owners and it is a condition of accessing publications that users recognise and abide by the legal requirements associated with these rights.

- Users may download and print one copy of any publication from the public portal for the purpose of private study or research.

- You may not further distribute the material or use it for any profit-making activity or commercial gain

If the publication is distributed under the terms of Article $25 \mathrm{fa}$ of the Dutch Copyright Act, indicated by the "Taverne" license above, please 


\title{
A GENERAL INVERSION CELL, OBTAINED FROM TWO RANDOM CONTRA-PARALLELOGRAM LINKAGES, INTERCONNECTED AT THE VERTICES OF A PARALLELOGRAM
}

\author{
EVERT A. DIJKSMAN \\ Mechanism and Machine Theory, Precision Engineering. Faculty of Mechanical Engineering. \\ Eindhoven University of Technology. Eindhoven. The Netherlands
}

(Receited 22 March 1993: in revised form 12 August 1993: received for publicasion 6 October 1993)

\begin{abstract}
It is possible to interconnect two dissimilar contra-parallelgram four-bar linkages by four turning-joints in a manner that permits (overconstrained) motion. These joints are located at the four vertices of a parallelogram. During the motion, the angles enciosed between the sides of this parallelogram do not vary, but the lengths, of which their product remains a constant, do. The overconstrained linkage mechanism. leads to the derivation of an entirely new inversion mechanism. Its inversion-cell is a 6-bar linkage of Watl's type. simply obtained from the combined linkage by erasing two interconnected bars with their turning-joints. One may show that Peaucellier's inversion-cell just appears as a very special case.
\end{abstract}

\section{INTRODUCTION}

There are many examples of overconstrained linkage mechanisms. One type is the one obtained by excessive interconnection of two four-bar linkages. Kempe [1] as well as Burmester [2] succeeded in doing this in different ways. Both obtained overconstrained 8-bar linkages with 2 excessive turning-joints. They took reflected-and directly similar four-bars and interconnected corresponding sides with a common turning-joint. One particular type, however, was not noticed, namely the one derived by the author at the occasion of the 7th World Congress on the Theory of Machines and Mechanisms, Sevilla in 1987 [3]. Then, the author took two random and thus dissimilar contraparallelogram linkages and interconnected corresponding sides with common turning-joints. To get this done, he first replaced the contra-parallelograms in a rigid way namely such that they got a common axis of symmetry. Then, one of them was shifted along the axis until $\Varangle(B D, B D)$ became $\pi$ radians. (See the obtained, relative position of the contra-parallelograms ASAS and CRCR in Fig. 1.) In this position, the contra-parallelograms were said to be perspective, since apparently corresponding joints were aligned with a common perspectivity center $T$. (Thus, $\square$ ASAS $\square C R C R$.) To prove this it is sufficient to show that the intersection point $T$, defined as (AC $\times S R$ ), actually joins the axis of symmetry. (Use Desargues' Theorem about perspective triangles to complete the proof.) Anyway, in this position, corresponding sides of the two contraparallelograms intersected at the points $D, B, B$ and $D$ of a straight-line running parallel to the diagonals of the contra-parallelograms. (See Ref. [3].) It appeared possible to turn the intersections into turning-joints, interconnecting these two particular four-bar linkages in an excessive way.

Reobserving the overconstrained 8-bar linkage from a different angle, one notes that actually, two intersion-cells of Hart are interconnected at these aligned turning-joints meeting the property that $|O P| \cdot|O Q|=$ constant with $O \equiv D, P \equiv B, Q \equiv B$ (and $U \equiv D$ ). Thus, as has been shown already by the author [4], the common turning-joints coincide with the points $O, P, Q$ (and $U$ ) of Hart's intersion-cell. In fact, by interconnecting two of these cells at these points, one regains the combined linkage mentioned earlier. Clearly, the four times overconstrained linkage mechanism may still be used as an inversion mechanism. (Four times, if we count turning-joints for two coordinates in design.)

At this point, it becomes possible to obtain even new inversion-cells by erasing the two ternary links interconnected at the fourth point $D \equiv U$. (See again Fig. I and also Ref. [4].) The result 


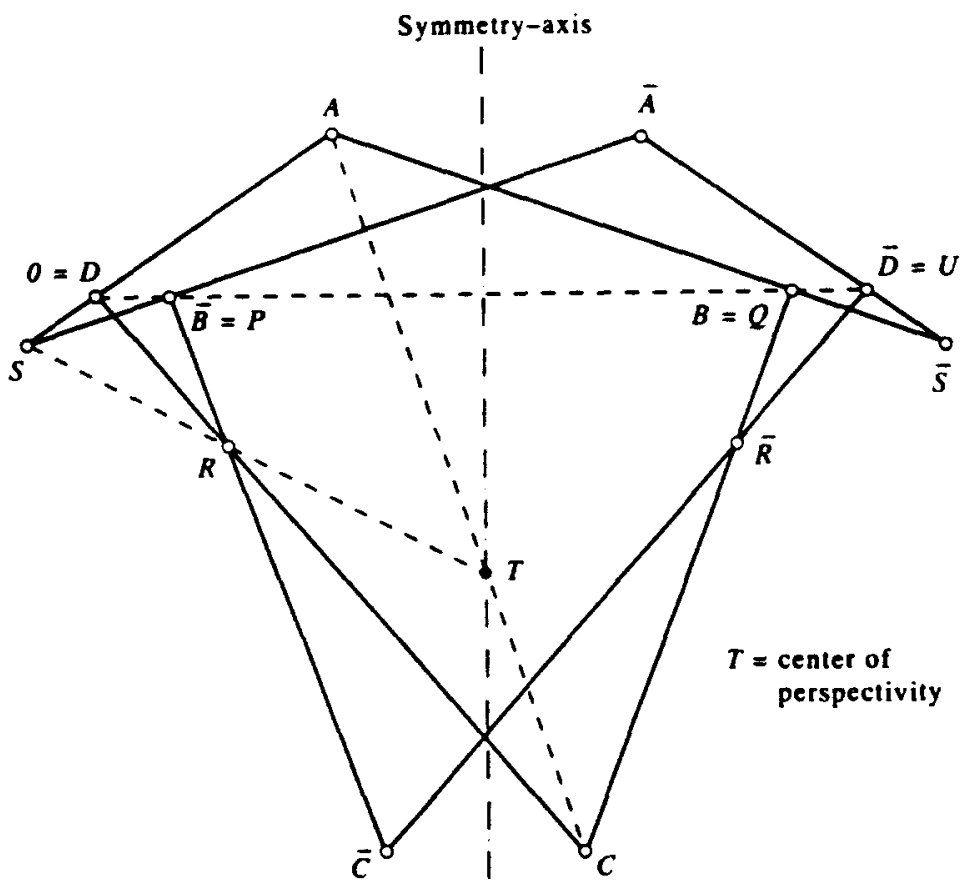

Fig. I. Two perspective anti-parallelogram linkages excessively interlocked through 4 turning-joints. forming an aligned parallelogram DBDB.

appeared to be a generalization of Peaucellier's inversion linkage. On the other hand, the two contra-parallelogram linkages excessively interconnected as demonstrated in Fig. 1 (as well as at the World Congress in Sevilla), will overcome their stretched or aligned positions through the very existence of their twin-brother. One may even erase one of the 8 bars, and still maintain this practical property. Then, a 7-bar, now singular overconstrained linkage chain, is obtained, still doing its job of maintaining contra-paralleiogram motion. The three adjoined bars then prevent transition into the parallelogram-mode.

\section{GENERALIZATION OF THE COMBINED CONTRA-PARALLELOGRAMS}

In 1971, the author showed the mechanical cognation between the inversion cells of Hart and Peaucellier [5]. He did this by application of his cognate-theory at 6-bar linkages of Watt's type [9]. Note that two linkages are said to be cognated if there is a pure mechanical way to interconnect the two of them in an overconstrained way by a certain number of common turning-joints and common links. Observed separately, the two linkages must be able to carry out identical objectives in every corresponding position. (Consider, for instance, Roberts' Law resulting into three four-bar curve-cognates, producing identical curves.) In the course of his proof, the author similarly showed mechanical cognation between Hart's inversion-cell and its more generalized form, the so-called quadruplanar inversion-cell of Sylvester and Kempe. This was simply done by stretch-rotation, being basically a similarity transformation of sub-chains and therefore a powerful tool to prove cognate theory as, for instance in the case of Roberts' Law.

The quadruplanar inversion-cell is to be obtained as follows (see Fig. 2, or alternatively, Fig. 5 of Ref. [5]):

(a) Start from Hart's inversion-cell ASAS containing the aligned points $O, P, Q$ and $U$.

(b) Stretch-rotate the contra-parallelogram ASAS about A with the randomly chosen complex factor $\mathbf{A S}^{\prime} / \mathrm{AS}$ into the contra-parallelogram $A S^{\prime} \bar{A} \cdot \mathbf{S}^{\prime}$.

(c) Attach $S^{\prime}$ to link ADS and $S^{\prime}$ to link AQS.

(d) Stretch-rotate the linkage-dyad PSD about D with the complex factor DS'/DS into the dyad P'S'D.

(e) Attach $P^{\prime}$ to $S^{\prime} \bar{A}^{\prime}$ and note the similarities of the triangles $P^{\prime} S^{\prime} \bar{A}^{\prime}$ and $\mathrm{DS}^{\prime} A$.

(f) Stretch-rotate the linkage-dyad QSU into QS'Q' about $Q$. 


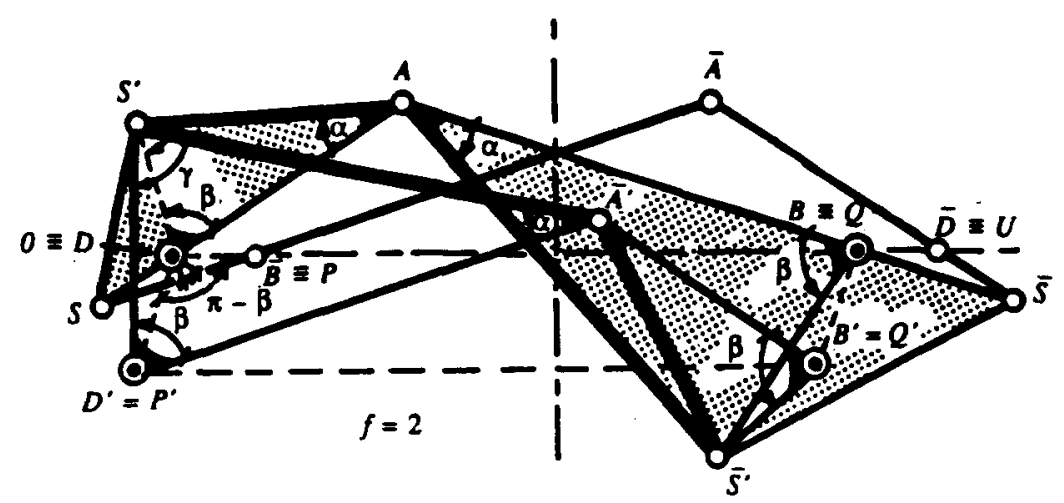

Fig. 2. Quadruplanar inversion-cell of Sylvester and Kempe obtained from Hart's cell of inversion through cognation.

(g) Finally, attach $Q^{\prime}$ to $S^{\prime} \bar{A}$.

(h) Note that the quadrilateral DP'Q' $Q$ represents a parallelogram with fixed angles but varying sides for which $\left|\mathrm{OP}^{\prime}\right| \cdot|\mathrm{OQ}|=$ constant (i.e. independent of a motion variable).

As the combined 8-bar linkage of Fig. I contains two contra-parallelograms, and therefore also two of cells of Hart, generalization of each of these cells must be possible. Say, random stretch-rotation and generalization turns the first contra-parallelogram linkage into some quadruplanar inversion-cell of Sylvester and Kempe. The latter then contains four new fundamental points, to wit: the old points $O \equiv D$ and $B \equiv Q$ in addition to the new points $D^{\prime} \equiv P^{\prime}$ and $B^{\prime} \equiv Q^{\prime}$ obtained with the transformation. The new points, $P^{\prime}, O, Q$ and $Q^{\prime}$, replacing the former points $P, O, Q$ and $U$ of Hart's cell, do form a parallelogram with varying sides enclosing constant angles, namely $\pi-\beta$ and $\beta$, the top-angle of the attached triangles. Further, the product of two different lengths of these sides, is independent of any motion variable. (See again Fig. 2.) The newly obtained fundamental points are now to be used as common turning-joints between the first and the second quadruplanar inversion-cell of Sylvester and Kempe. Permissable only, if the second one, obtained by generalization of the second contra-parallelogram, obtains the same fundamental points $\mathbf{P}^{\prime}, \mathrm{O}, \mathrm{Q}$ and $\mathrm{Q}^{\prime}$ after transformation. Whence the (second) generalization of the second contra-parallelogram, is not a randomly chosen one like the first generalization, but fully depends on the first generalization.

The details of the generalization now directly applied on the kinematic chain of Fig. 1, will be given through the assignments (see Fig. 3):

(a) Start the design with the two (four times) interconnected contra-parallelogram chains ASÁS and CRCR as demonstrated in Fig. 1.

(b) Stretch-rotate the contra-parallelogram linkage ASAS about $A$ with the random and complex factor $f_{x}=S^{\prime} \mathbf{A} / \mathbf{S A}$, resulting into the contra-parallelogram linkage AS' $\bar{A}$ 'S' similar to ASĀS.

(c) Form the rigid and similar triangles ASS' and ASS'.

(d) Form the rigid and mutually similar triangles A'D'S', ADS', ABS' and A'B' $\mathrm{S}^{\prime}$.

(e) Note that $\left|\mathrm{OP}^{\prime}\right| \cdot|O Q|=\left(\left|\mathrm{DS}^{\prime}\right| /|\mathrm{DS}|\right)|\mathrm{OP}| \cdot|\mathrm{OQ}|=\left|\mathrm{S}^{\prime} D\right| \cdot\left|\mathrm{DA}^{\prime}\right|\left\{\left(\left|\mathbf{S}^{\prime} \mathrm{A}^{\prime}\right|^{2} /\left|\mathbf{S}^{\prime} A\right|^{2}\right)-1\right\}=$ constant, whereas also $\measuredangle \mathrm{QOP}^{\prime}=\pi-\beta=$ constant.

(f) Remark that the linkage-dyad DSP has been stretch-rotated about $D$ into the linkage-dyad DS'P', making $\triangle$ DS'P' $\sim \triangle$ DSP.

(g) Now, stretch-rotate the linkage-dyad DRP into DR'P', similarly making $\triangle D^{\prime} P^{\prime} \sim$ $\triangle$ DRP. Thus, $\square S^{\prime} P^{\prime} R^{\prime} D \sim \square$ SPRD, whence the four-bar SPRD has been stretchrotated about its turning-joint $D$ into the four-bar S'P'R'D.

(h) Stretch-rotate the rigid $\triangle C^{\prime} R^{\prime}$ into the similar $\triangle C^{\prime} R^{\prime}$ (also rigid), determining turning-joint R:

(i) Stretch-rotate the contra-parallelogram chain CRCR about $C$ into the similar contraparallelogram-linkage $C R^{\prime} C^{\prime} R$ '.

(j) Form the rigid and mutual similar triangles $C^{\prime} R^{\prime} D^{\prime}, C^{\prime} D, C R \cdot Q$ and $C^{\prime} R^{\prime} Q^{\prime}$. 


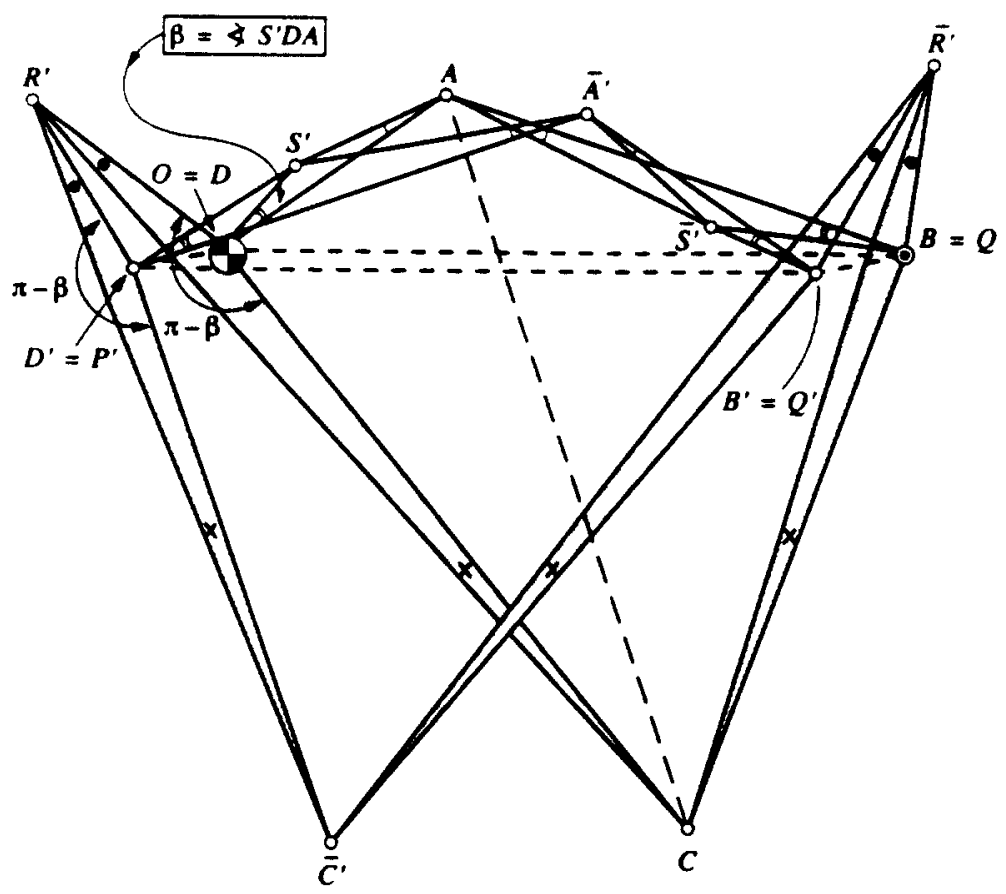

Fig. 3. Two dissimilar quadruplanar inversion-cells interlinked at $D^{\prime} D^{\prime} B$ forming a parallelogram for which $\overline{O^{*}} \cdot \overline{\mathbf{O Q}^{\prime}}=$ constant while $\triangle \mathrm{QOP}^{*}=\pi-\beta$.

The two contra-parallelogram-linkages AS'A'S' and CR'C'R' now possess the common turningjoints $\mathrm{D}, \mathrm{B}, \mathrm{B}$ and $\mathrm{D}^{\prime}$. Clearly, the common joints form a parallelogram with varying sides enclosing angles being independent of the motion variable. Though the two contra-parallelogramlinkages, contained in the 8-bar, are not similar, the two quadruplanar inversion-cells (of Sylvester and Kempe) may be regarded as cognates, having four common turning-joints forming a common parallelogram DBB' ${ }^{\circ}$, whereas both sustain the identical property of inverting planar curves in the same way. The 8-bar linkage-combination, just designed, represents the most generalized possibility to interconnect two entirely different contra-parallelogram linkages in this excessive way. Studying the number of degrees of freedom in design of this 8-bar, one notes that the 2 nd quadruplanar inversion-cell is completely determined by the first and the linkage-dyad DR'D', the latter being linked to the first cell at $D$ and $D^{\prime}$. Thus, two additional coordinates for joint ' ${ }^{\prime}$ ' in addition to those determining the first quadruplanar inversion-cell. Both cells possess the same top-angles $\beta$ (eventually differing $\pi$ radians) of the rigidly attached triangles, but the corresponding base-angles are generally different. Further note that any pair of triangles with a common vertex possess either the same top-angle at that vertex, or have otherwise top-angles differing $\pi$ radians.

An easier running but more direct, design of the combined (8-bar) linkage-configuration, would read something like this (see Fig. 3):

(a) Start with the choice of a random four-bar ABCD.

(b) Choose a random turning-joint $S$ ' in the moving plane of DA.

(c) Draw the similar triangles $A S^{\prime} D$ and $A S^{\prime} B$, and determine point $S^{\prime}$.

(d) Next, draw the contra-parallelogram AS'A'S:

(e) Reflect the four-bar $A B C D$ about a perpendicular of DB and shift her reflection to the four-bar $\bar{A}^{\prime} D^{\prime} C^{\prime} B^{\prime}$. (Verify the similarity of the triangles $A S^{\prime} B$ and $\bar{A}^{\prime} S^{\prime} B^{\prime}$, further note that $\square$ DBB'D' represents a parallelogram.)

(f) Determine R' such that $\measuredangle C^{\prime} R^{\prime}=\pi-\measuredangle S^{\prime} D A=\measuredangle C^{\prime} D^{\prime} R^{\prime}$ (i.e. $\triangle C^{\prime} R^{\prime} \sim \triangle C^{\prime} D^{\prime} R^{\prime}$ ).

(g) Draw the contra-parallelogram $C R^{\prime} C^{\prime} R^{\prime}$ and draw its similar and rigid triangles $C D R$ ', $C^{\prime} D^{\prime} R$ ', C'B'R' and CBR'.

This establishes the design of the generalized 8-bar containing two quadruplanar inversion-cells of Sylvester and Kempe being interconnected through the 4 turning-joints D,D', B' and B, forming a parallelogram for which $\left|\mathrm{DD}^{\prime}\right| \cdot|\mathrm{DB}|=$ constant as well as $\measuredangle \mathrm{BDD}^{\prime}=\pi-\beta=$ constant (see 
Fig. 3). The (four times) overconstrained, now generalized inversion-cell corresponds even to an infinite number of cells as demonstrated in Fig. 1. One of them may be obtained as follows:

(h) Take a random point $S$ at $A D$ or at its prolongation.

(i) Make the four-bar SBRD similar to the four-bar $S^{\prime} D^{\prime} R^{\prime} D$, yielding the points $B \equiv P$ and $\mathbf{R}$.

(j) Determine $T$ at the intersection of $A C$ and $S R$.

(k) Draw the symmetry-axis, joining $T$, running normal to $B D$.

(l) Determine the image-points $\bar{A}, D, S, R$ and $C$.

The design of the generalized 8-bar clearly needs 10 co-ordinates, i.e. eight for the random choice of the four-bar ABCD and two for the random choice of point $S^{\prime}$ in the plane attached to DA. (The choice of point $S$ is not necessary for the determination of the generalized 8-bar.)

\section{NEW INVERSION-CELL}

The general 8-bar linkage, obtained from the four times overconstrained linkage chain of Fig. 1, naturally, is quadruple overconstrained too. As a consequence, two ternary links having a common turning-joint, say the ones with their top-angle at their common turning-joint B', may be omitted. The 8-bar linkage chain then turns into a six-bar linkage of Watt's type (see Fig. 4). The remaining linkage then consists of a random four-bar, $A B C D$, and the linkage-dyad $S^{\prime} D^{\prime} R^{\prime}$. The turning-joints $S^{\prime}$ and $R^{\prime}$ of this dyad, are the vertices of the rigid triangles $S^{\prime} D A$ and $R^{\prime} D C$, rigidly attached to the respective sides DA and DC of the initial four-bar ABCD. Both triangles attached to the four-bar, possess either the same angle $\beta$ at the common vertex $D$, or have angles at $D$ being each other's supplement. The other corresponding angles are generally different. Only in case the initial four-bar $A B C D$ has perpendicular diagonals $A C$ and $B D$, the attached pair of triangles are similar. (Then, the four-bar R'D'S'D possesses perpendicular diagonals too; thus, $R^{\prime} S^{\prime} \perp D^{\prime} D$ in that case.)

The general design of the incersion-cell may now be obtained through the following assignments (see Figs 3 and 4):

(1) Start the design with a random four-bar ABCD.

(2) Choose a random turning-joint $S^{\prime}$ in the moving plane of DA.

(3) Determine the image $A B_{1}$ of $A B$ with respect to the normal of $B D$ passing through $A$.

(4) Make $\triangle D^{\prime} D^{\prime}$ similar to $\triangle D A B_{i}$ and establish the location of turning-joint $D^{\prime} \equiv P^{\prime}$.

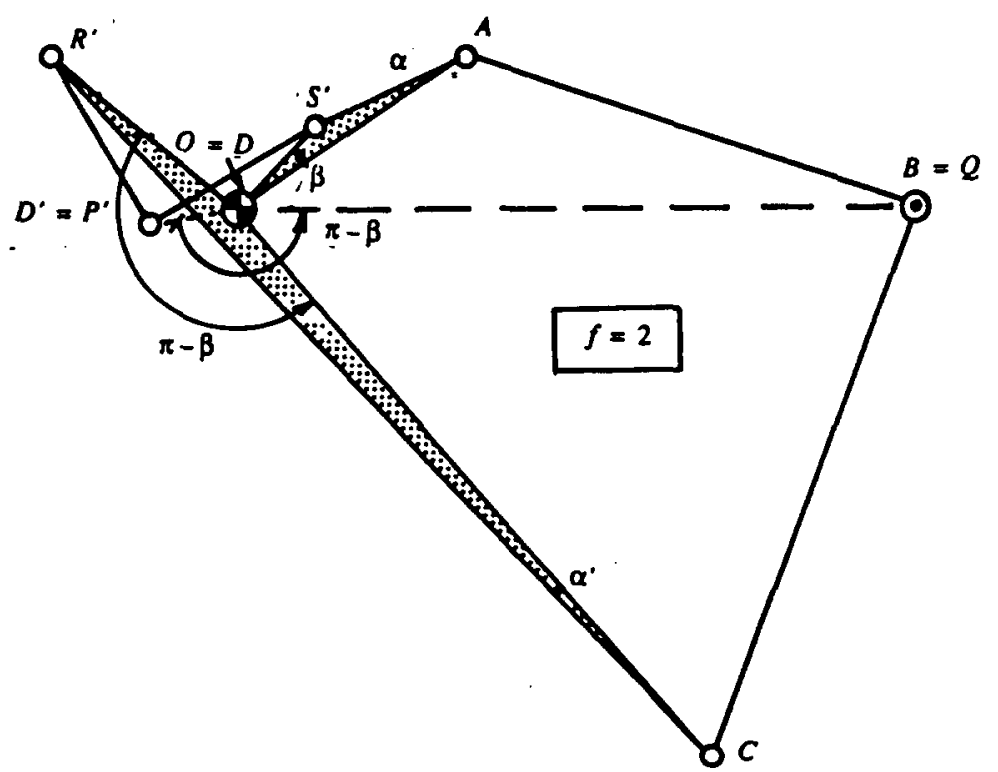

Fig. 4. New inversion cell with a random 4 -bar $A B C D$ and a random joint $S^{\prime} \cdot \overline{O P}: \overline{O Q}=$ constant. 


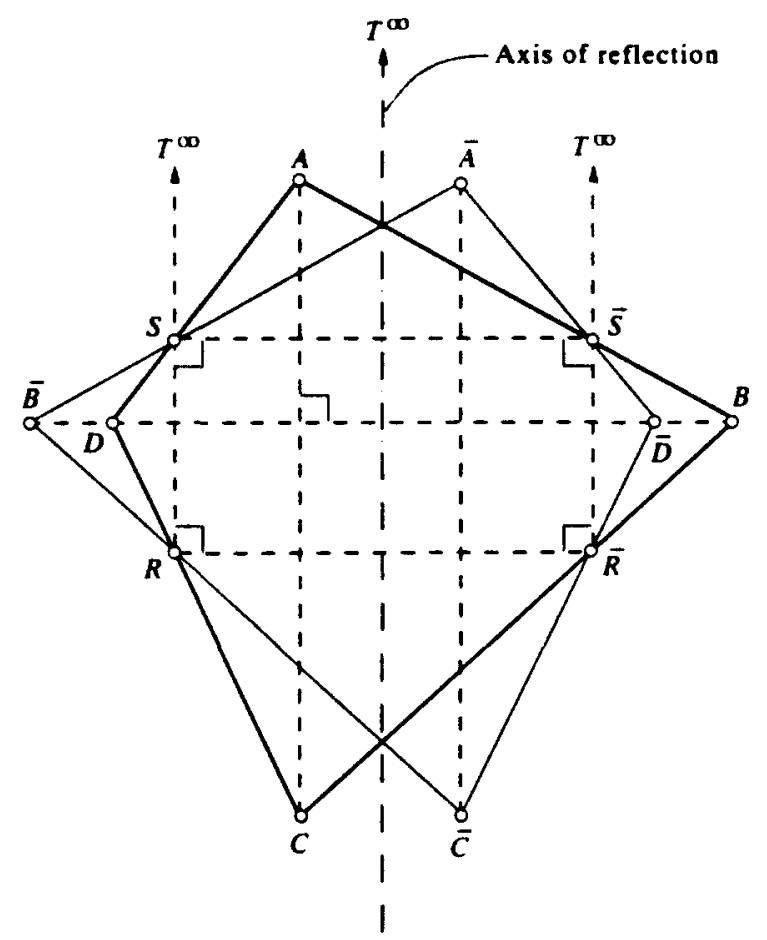

Fig. 5. Special case with $\mathbf{T} \rightarrow \infty$ (reflected 4-bars with perpendicular diagonals).

(5) Determine the image $\mathrm{CB}$, of $\mathrm{CB}$ with respect to the normal of $\mathrm{BD}$ joining $\mathrm{C}$.

(6) Make $\triangle D^{\prime} D^{\prime}$ similar to $\triangle D C B$, and determine turning-joint $R^{\prime}$.

It is now possible to prove that the so-obtained cell indeed meets the two conditions for geometric inversion for any value of the motion-variable, namely:

$\left|\mathrm{OP}^{\prime}\right| \cdot|\mathrm{OQ}|=|\mathrm{DA}| \cdot\left|\mathrm{DS}^{\prime}\right|\left\{1-\left(\left|\mathrm{S}^{\prime} \bar{A}^{\prime}\right|^{2} /\left|\mathrm{S}^{\prime} A\right|^{2}\right)\right\}=$ constant, and $\measuredangle \mathrm{QOP}^{\prime}=\pi-\beta=$ constant.

(Note, that by agreement $O \equiv D, P^{\prime} \equiv D^{\prime}, Q \equiv B, Q^{\prime} \equiv B^{\prime}, U \equiv D^{\prime}$ and $P \equiv B^{\prime}$ )

Taking point $\mathrm{O} \equiv \mathrm{D}$ as a fixed turning-joint, any circle traced by $\mathrm{P}^{\prime}$ will then be transformed into the inverse circle, traced by point $Q$, and conversely.

Apart from the four sides of the random four-bar, the inversion-cell is determined by 2 additional design-degrees of freedom, namely two for the random choice of $\mathbf{S}$.

In the particular case for which the four-bar $A B C D$ has perpendicular diagonals, the rigid triangles $R^{\prime} D C$ and $S^{\prime} D A$ become similar, whereas the 2nd four-bar $S^{\prime} D^{\prime} R^{\prime} D$, comprised in the cell, will also get perpendicular diagonals.

(Note that, according to Ref. [8], the perpendicularity between the diagonals of the four-bars remains true for the entire motion of the cell.) In that case I degree-of-freedom-in-design has been lost. See also Fig. 8, or Fig. 10 of Ref. [4] in this particular case.

In the very particular case for which the four-bar $A B C D$ represents a kite and further $R^{\prime}=C$, one regains Peaucellier's inversion-cell, also containing 6 links (see again Ref. [4]).

\section{Particular CaSe}

An interesting case occurs when the perspectively-center $T$ of Fig. 1 goes to the infinite. Thus, when $T=T^{x}$. Then, all four-bars, with the exception of the two contra-parallelograms, have perpendicular diagonals (see Fig. 5 and also Fig. 8 of Ref. [3]).

Note that once the diagonals of a four-bar linkage are perpendicular, they remain perpendicular throughout the complete motion; a proposition easily proved through the knowledge that it is possible to move any linkage-polygon, though its turning-joints remain at perpendicular axes causing each side to produce the elliptic motion (see Figs 6 and 14 of Ref. [6], and also Ref. [8]). 


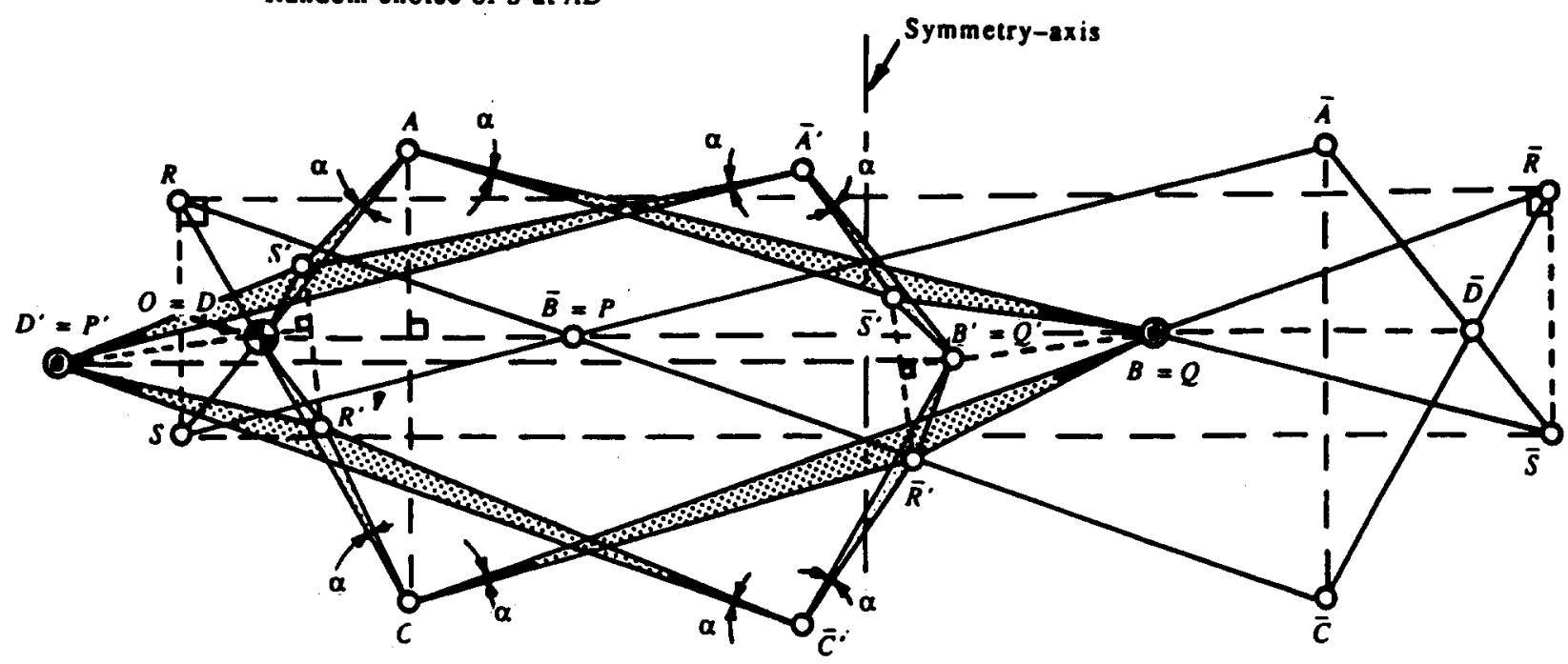

Fig. 6. Derivation of a generalized configuration containing 4 four-bar linkages with perpendicular diagonals.

Generalization of Fig. 5, like we did with Fig. 1, interconnecting two quadruplanar inversion-cells of Sylvester and Kempe, produces equally similar four-bars as in the case of Fig. I (see Fig. 6):

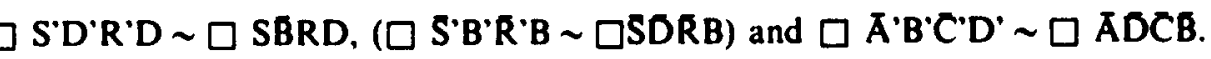

(Corresponding sides of $A^{\prime} B^{\prime} C^{\prime} D^{\prime}$ run even parallel to those of $A D C B$ !) We even find that two pairs of reflected equal four-bars, namely (S'D'R'D with $\left.S^{\prime} B R^{\prime} B^{\prime}\right)$ as well as the pair (ABCD with $\left.A^{\prime} D^{\prime} C^{\prime} B^{\prime}\right)$ all possess perpendicular diagonals. As Fig. 5 further shows that $\triangle A D C \sim \triangle S D R$, the similarity between the four-bars $\square S^{\prime} D^{\prime} R$ 'D and $\square$ SBRD just results into the equations:

$$
R^{\prime} D / S^{\prime} D=R D / S D=C D / A D \text {. }
$$

As finally, $\measuredangle R^{\prime} D C=\pi-\measuredangle R^{\prime} R^{\prime}=\pi-\measuredangle S^{\prime} S^{\prime}=\measuredangle S^{\prime} D A=\beta$, we find that in this case, $\triangle R^{\prime} \mathbf{D C} \sim \triangle \mathbf{S}^{\prime} \mathbf{D A}$.

Since each of these triangles are similar to three others, each of them being attached to a different side of a contra-parallelogram, all eight triangles, i.e. $\triangle A D S^{\prime}, A B S^{\prime}, C^{\prime} R^{\prime}, C^{\prime} R^{\prime}, C^{\prime} D^{\prime} R^{\prime}$, $A^{\prime} D^{\prime} S^{\prime}, A^{\prime} B^{\prime} S^{\prime}$ and $C^{\prime} B^{\prime} R^{\prime}$, are all mutually similar (see Fig. 7). This shows that when two pairs of reflected equal four-bars, contained in the generalized 8-bar, all have perpendicular diagonals, not only the top-angles $(\beta)$, but also the corresponding base-angles $(\alpha)$ have to be the same in that particular case.

(Thus, $\measuredangle$ DAS $^{\prime}=\measuredangle$ BASS' $=\measuredangle \ldots=\alpha$. See Fig. 7 and also Ref. [4].)

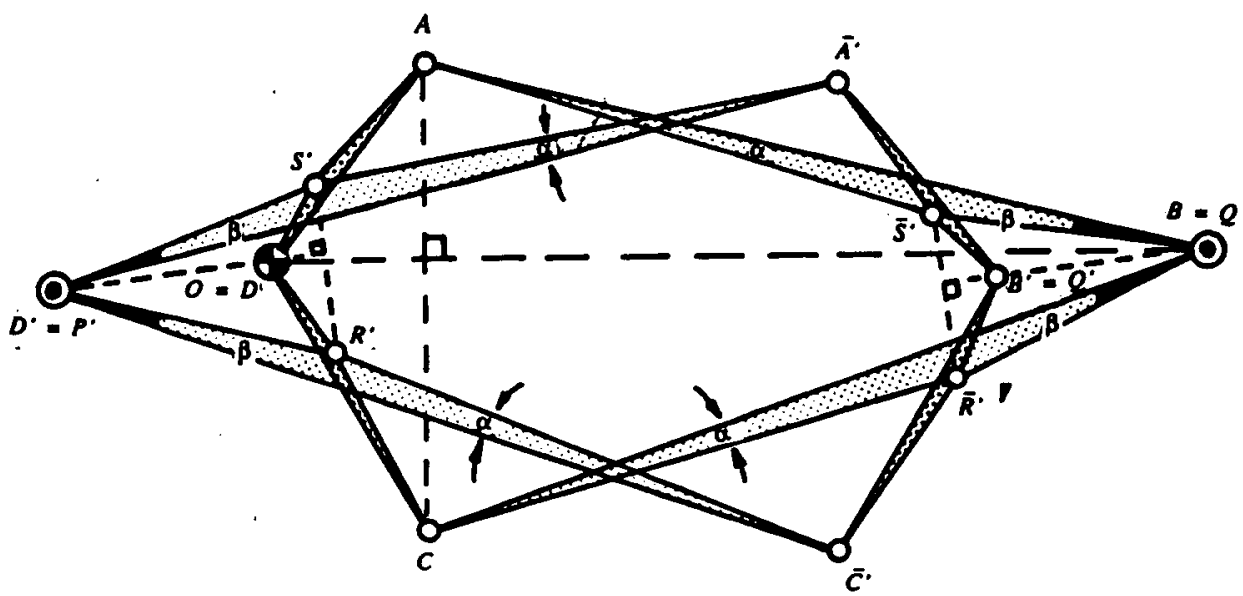

Fig. 7. Special case with 8 similar triangles. 


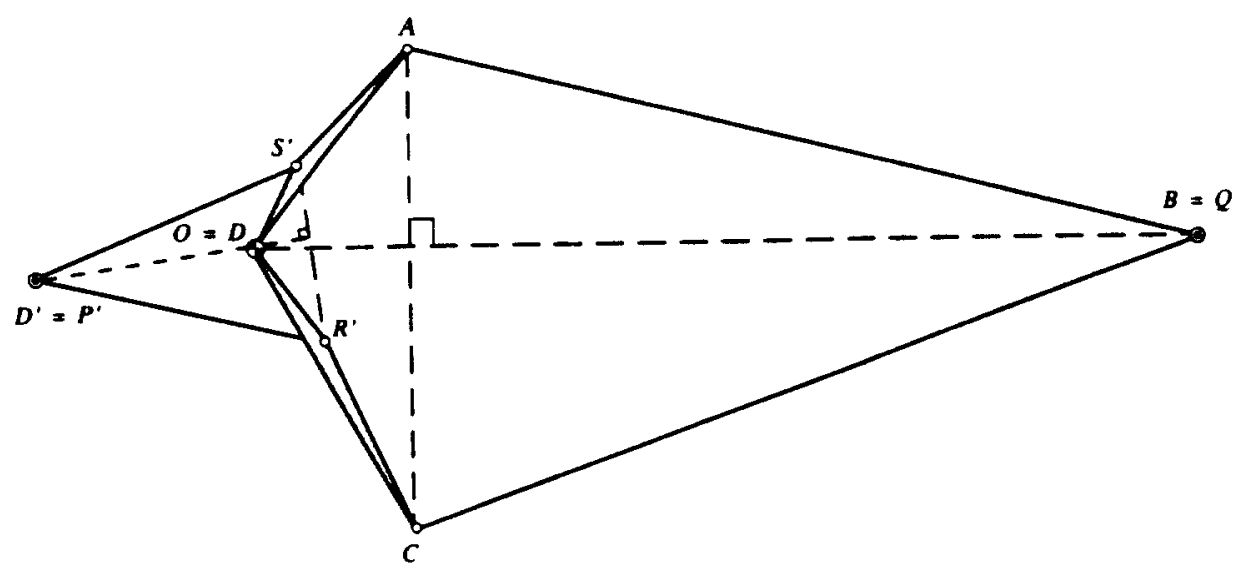

Fig. 8. Particular inversion-cell.

The instructions for the design of the 8-bar inversion-cell in this case would now read like:

(a) Take a random four-bar linkage $A B C D$ having perpendicular diagonals.

(b) Choose a random point $S^{\prime}$ in the moving plane attached to $A D$.

(c) Make $\triangle A^{\prime} D \sim \triangle A^{\prime} S^{\prime} B \sim C^{\prime} R^{\prime} B \sim \triangle C^{\prime} D$.

(d) Draw the contra-parallelogram linkages $A S^{\prime} A^{\prime} S^{\prime}$ and $C R^{\prime} C^{\prime} R$ '.

(e) Make $\triangle C^{\prime} D \sim \triangle C^{\prime} R^{\prime} D^{\prime} \sim \triangle C^{\prime} R^{\prime} B^{\prime} \sim \triangle A^{\prime} S^{\prime} B^{\prime} \sim \triangle A^{\prime} S^{\prime} D^{\prime}$.

(f) Verify the parallelograms $D^{\prime} D^{\prime} B$ and $S^{\prime} R^{\prime} R^{\prime} S^{\prime}$.

(g) Verify the reflected congruency of the four-bar linkages $A B C D$ and $A^{\prime} D^{\prime} C^{\prime} B$ '.

(h) The same for the reflected equal four-bars $S^{\prime} D^{\prime} R^{\prime} D$ and $S^{\prime} B R \cdot B^{\prime}$.

(i) Finally, verify the perpendicularity of the diagonals in each of the four quadrilaterals, mentioned under $(\mathrm{g})$ and $(\mathrm{h})$.

\section{REMARKS}

(1) An infinite square number of linkages demonstrated in Fig. 3 are to be obtained from the linkage of Fig. 1. However, for the incerse procedure, we find that an infinite number of Fig. 1 linkages are to be obtained from the configuration of Fig. 3.

(2) The obtained linkage of figure 3 looks very much alike a generalized focal linkage of Kempe. But it is not. This is best demonstrated by drawing a so-called merging figure representing a special case of Fig. 1 by which SR and DB intersect at the symmetry-axis: by disengaging the turning-joints at $S, S, R$ and $R$, and simultaneously turning the four intersection-points $(A D \times C B),(B A \times D C)$, $(C B \times A D)$ and $(D C \times B A)$ into turning-joints, only then a special case of a generalized focal linkage of Kempe is obtained (see also the merging Fig. 6 of Ref. [3]).

\section{REF ER ENCES}

1. A. B. Kempe, Proc. Lond. Math. Soc. 9, 133-147 (1878).

2. L. Burmester, Allas zu Lehrbuch der Kinematik, Erster Band, Die ebene Beweging. Taf.XXXVII und XXXVIII (fig. 597-626). Leipzig (1888).

3. E. A. Dijksman. Proc. 7h World Cong. on TMM. Sevilla, Vol. I. pp. 69-73 (1987).

4. E. A. Dijksman, Proc. 6ih Int. Symp. on Linkages and Computer Aided Design Methods (Theory and Practice of Mechanisms). Vol. I. Paper 10. pp. 73-82. SYROM 93. București. Romània (1993).

S. E. A. Dijksman. J. Engng Ind. Trans. ASME Ser. B 93, 334-339 (1971).

6. E. A. Dijksman. Proc. 8ih World Cong. on the Theory of Machines and Mechanisms, Vol. 1, pp. 29-33, Prague (1991).

7. E. A. Dijksman. Motion Geometry of Mechanisms. Cambridge University Press, Cambridge (1976). Cinemática de Mecanismos, Editorial Limusa, S.A., Cap. 8, pp. 227-236 (1981).

8. R. Bricard, Lecons de Cinemarique, Tome II. Chap. XIX, pp. 157-158. Gauthier-Villars. Paris (1927).

9. E. A. Dijksman. J. Engng Ind. Trans. ASME Ser. B 93, 183-190 (1971).

10. I. I. Artobolevskii, Mechanisms for the Generation of Plane Curtes. Pergamon Press, Oxford (1964). 


\section{DOS CONEXIONES DE PARALELOGRAMOS NO SIMILARES CONECTADAS EN LOS VERTICES DE UN PARALELOGRAMO}

Resamea-A pesar de una supuesta limitación del movimiento, se pueden conectar dos conexiones de contraparalelogramos completamente diferentes de una manera excesiva con hasta cuatro puntos de gira (normales). colocados en los vértices de un paralelogramo. Durante el movimiento los ángulos encerrados entre los lados de este paralelogramo no varian, pero la longitud si varia aunque el producto continúa constante. El superlimitado mecanismo de conexión en general lleva a la derivación de un mecanismo de inversión completamente nuevo. Su célula de inversión es una conexión de seis barras de tipo Watt. obtenida simplemente del punte de gira conectado. eliminando dos barras conectadas con sus puntos de gira. Se puede probar que la célula invertida de Peaucellier sólo aparece como un casa muy especial. 